Artigo recebido em 18/03/2014

Aprovado em $12 / 05 / 2014$

ALEXANDRE

BARBOSA

UNIVERSIDADE

NOVE DE JULHO - prof. alexandrebarbosa@gmail.com alexandre@latinoamericano.jor.br

Doutor em Ciências da Comunicação

(ECA-USP), Mestre em Ciências da

Comunicação (ECAUSP), Especialista em Jornalismo Internacional

(PUC-SP), Jornalista

(UMESP). Professor e coordenador do curso de Jornalismo da Universidade Nove de Julho (SP). Editor do site www.latinoamericano.jor.br
Estudos em Jornalismo e Mídia Vol. $11 \mathrm{~N}^{\circ} 1$ Janeiro a Junho de 2014 ISSNe 1984-6924

\section{Boletim Sem Terra: organizador coletivo dos trabalhadores rurais como estratégia de resistência à ditadura militar}

Alexandre Barbosa

\section{Resumo}

Este artigo mostra como o Boletim Sem Terra, publicação da fase embrionária do MST, foi utilizado como organizador coletivo dos trabalhadores rurais durante os últimos anos da ditadura militar brasileira. Essa função do jornal foi descrita por Lenin na obra O Que Fazer? e contribui na compreensão das características da política de comunicação do movimento nos seus primeiros anos de ação e para estudar como os trabalhadores rurais conseguiram se organizar mesmo com a repressão. Com o auxílio da Comissão Pastoral da Terra, o Boletim Sem Terra torna-se um órgão do movimento e aos poucos contribui para a formação da identidade nacional de um dos maiores movimentos sociais brasileiros.

Palavras-chave

MST, Organizador coletivo, Movimentos sociais na ditadura militar.

\begin{abstract}
This article shows how the Landless Bulletin, published in the embryonic stage of the MST, was used as a collective organizer of rural workers during the last years of the Brazilian military dictatorship. This feature of the newspaper was described by Lenin in the work What to do? and contributes to the understanding of the characteristics of the communication policy of the movement in its early years of action and to study how rural workers even managed to organize, although the crackdown. With the help of the Pastoral Land Commission, Bulletin of the Landless becomes an organ of motion and gradually contributes to the formation of the national identity of one of the most important social movements in Brazil.
\end{abstract}

Keywords

MST, Collective organizer, Social movements against dictatorship. 


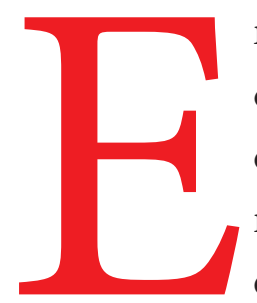

m maio de

de

1981 , quando as 300 famílias de trabalhadores rurais acamparam no entroncamento de estradas próximo ao município de Ronda Alta, conhecido como Encruzilhada Natalino, no Rio Grande do Sul, as condições eram as mais precárias, tanto do ponto de vista da vida humana quanto do ponto de vista político: o hospital mais próximo ficava a cerca de 19 quilômetros do acampamento, faltavam alimentos, o frio do outono já castigava as famílias, o Brasil ainda vivia sob uma ditadura militar e muitos governos locais, como o do Rio Grande do Sul à época, não levavam em consideração as demandas da classe trabalhadora.

Mesmo em meio a condições adversas, as famílias mantiveram o espírito de organização coletiva e de compreensão de que apenas aquele tipo de luta -- a ideia de que o acampamento representava a pressão sobre o governo local -- poderia dar resultado. Os trabalhadores recusaram a saída proposta pelo governador da época e pelo Instituto de Colonização e Reforma Agrária (INCRA) de enviar as famílias para regiões no Norte do país, em terras sem condições de iniciar uma produção sustentável e sem o devido apoio financeiro.

Como instrumento integrante dessa conscientização política, em grande parte incentivada pela Comissão Pastoral da Terra (CPT), organização ligada a uma ala progressista da Igreja Católica, influenciada pela ideologia da Teologia da Libertação, nasceu o

1-A obra utilizada como referência para este artigo é a publicada, em 2010, pela editora Expressão Popular. embrião do Jornal Sem Terra, que circula de forma ininterrupta de 1981 até a atualidade, chamado, à época, de Boletim da Campanha de Solidariedade aos
Agricultores Sem Terra. A trajetória do Jornal Sem Terra, que começou como um boletim do que acontecia aos acampados no Rio Grande do Sul e hoje traz as experiências do MST em todos os estados em que está organizado, aproxima-se do que Lenin considerava o papel de um jornal: um organizador coletivo.

Insisto em que apenas se pode começar a criar essa ligação efetiva de união a partir de um jornal comum [...] empreitada única e regular de caráter nacional voltada para realizar a síntese de todas as atividades, mas mais variadas, de modo a incitar as pessoas a avançar constantemente por todos os numerosos caminhos que levam à revolução, como todos os caminhos levam à Roma. (LENIN, 2010, p.245-246)

Da mesma forma que o Movimento ocupou latifúndios improdutivos, como uma nova forma de luta pela reforma agrária, o MST soube recriar outras formas de luta política, incluindo a utilização dos diversos meios de comunicação disponíveis, desde jornais, passando pelas rádios comunitárias, até a Internet e as redes sociais que surgiram no início do século XXI. Neste artigo, será detalhado como o Boletim Sem Terra auxiliou o MST a se organizar em sua fase embrionária.

\section{Lenin e o jornal como organizador coletivo}

Em sua obra Que Fazer? Problemas candentes do nosso movimento, originalmente escrita entre 1901 e $1902^{1}$, Vladimir I. Lenin dedica-se a discutir os problemas centrais da teoria e da prática do processo revolucionário russo e dá as bases dos elementos fundamentais para a organização política das classes 
trabalhadoras.

O foco de Lenin nesse livro está na tarefa das organizações revolucionárias como responsáveis pela elevação da consciência de classe dentro das lutas "econômicas", ou seja, dentro das reivindicações mais imediatas dos trabalhadores: melhoria dos salários e das condições de trabalho, horas da jornada, entre outros.

No caso do Movimento dos Trabalhadores Rurais Sem Terra (MST), é possível perceber essa concepção da organização responsável pela educação política e formação da consciência de classe desde a fase embrionária do movimento, no início da década de 1980. Isso não quer dizer que o MST defina-se como um grupo de inspiração leninista, mas que é possível analisar algumas ações, como a criação do Jornal Sem Terra, a partir dos conceitos definidos por Lenin nessa obra.

\section{Lenin, além de} defender a criação e manutenção do jornal, preocupa-se para que ele seja de "toda a Rússia"

A luta pela Reforma Agrária poderia ser considerada pelos trabalhadores rurais como uma luta imediatista: a partir do momento em que se conquista uma terra, ou seja, em que uma família é assentada em uma propriedade para que possa nela trabalhar, a luta teria chegado ao seu objetivo final.

Porém, os trabalhadores rurais compreenderam que a luta pela reforma agrária também é política. Entre outras ideias, conscientizaram-se de que:

a) A Reforma Agrária não pode ser conquistada sem uma luta constante e que se proponha a alterar outras relações de poder, pois, no Brasil, assim como na América Latina, a propriedade de grande extensão de terra com finalidades políticas e especulativas está relacionada ao processo histórico de formação da nação;

b) As propostas de assentamento oferecidas ao longo da História não contemplavam a emancipação dos trabalhadores, pelo contrário, aumentavam a dependência em relação ao capital; c) Apenas com a união de trabalhadores do campo e da cidade, é possível obter os apoios necessários para a consolidação da luta;

d) Os trabalhadores e o movimento sofrem tanto com a violência física (pistoleiros e milícias dos fazendeiros) como com uma ostensiva campanha empreendida pela indústria jornalística, que procura não só diminuir o valor da luta, como, principalmente, criminalizar o movimento e seus integrantes;

e) Mesmo com a conquista da terra, outras lutas precisam ser travadas, pois é necessário erradicar o analfabetismo, ampliar a conscientização política no campo e na cidade, eleger parlamentares que tenham afinidade ideológica com o movimento e, em fase posterior, viver em uma sociedade 
em que a acumulação de capital não seja o elemento decisivo, ou seja, em uma sociedade socialista.

Em Que Fazer?, Lenin argumenta que um veículo de comunicação, desde que seguindo determinadas características, pode se tornar o que ele chamou de "organizador coletivo", principalmente dentro das condições da Rússia no início do século XX:

[...] de fato, não há outro meio para educar pessoas para formar organizações políticas fortes senão um jornal para toda a Rússia. [...] As massas nunca aprenderão a travar a luta política se não ajudarmos na formação de dirigentes para essa luta, oriundos tanto dos operários instruídos quanto dos intelectuais; tais dirigentes podem ser formados, exclusivamente, quando iniciados na apreciação sistemática e cotidiana de todos os aspectos da nossa vida política, de todas as tentativas de protesto e de luta das diferentes classes e por diferentes motivos. [...] o "trabalho político vivo" só pode começar exclusivamente através de uma agitação política viva, impossível de se realizar sem um jornal para toda Rússia, que apareça frequentemente e se difunda de forma regular. (LENIN, 2010, p.237239).

Lenin, além de defender a criação e manutenção do jornal, preocupa-se com o fato de que ele seja para "toda a Rússia", isto é, que seja elaborado para toda a nação e que contemple as diferentes lutas nos diferentes locais de um país em que se espera conscientizar a classe trabalhadora.

Luciano Gruppi (1978, p. 37) mostra que Que fazer? foi escrito quando o movimento operário russo continha poucos elementos de consciência política e ideológica, quando havia nele muita espontaneidade e quando o partido social-democrata russo estava nascendo, portanto, em uma situação muito próxima à dos trabalhadores rurais brasileiros em 1981: muita espontaneidade, muita vontade de conquistar a terra, mostrada pela disposição das famílias em ocupar as fazendas, mas uma organização ainda incipiente e uma condição política adversa, a ditadura militar.

Para Lenin, o partido é o momento da consciência de classe, o momento de dirigir essas reações espontâneas dentro de um projeto mais complexo de tomada do poder pela classe trabalhadora. No entanto, os movimentos espontâneos podem acontecer em diversas regiões do país e muitos poderão sofrer com repressões mais duras, o que enfraqueceria a luta como um todo. Por isso, ele ressaltava a necessidade de aglutinar essas ações espontâneas de toda a sociedade.

Nocasodomovimentodostrabalhadores rurais, houve a consciência de que, além das famílias acampadas no interior do Rio Grande do Sul, havia movimentações em outros estados e também em outras categorias profissionais. Segundo Lenin (2010), é atribuição do partido a tarefa de congregar essas diferenças manifestações em um trabalho que fosse comum, unitário e isso demandaria um trabalho de base. Lenin (2010,p.245) insiste que:

[...] apenas se pode começar a criar essa ligação efetiva de união a partir de um jornal comum, para toda a Rússia, empreitada única e regular de caráter nacional, voltada para realizar a síntese de todas as atividades, as mais variadas, de modo a incitar as pessoas a avançar constantemente por todos os 
numerosos caminhos que levam à revolução.

Mesmo sem caracterizar-se como um partido, o MST assumiu essa tarefa, expressando-se inicialmente por meio do Boletim Sem Terra e depois pelo Jornal Sem Terra, que, ao publicar reportagens e artigos, toma também como suas as lutas dos trabalhadores urbanos por melhores salários, pela consolidação da CUT, a campanha pelas Diretas, pela constituinte, entre outros temas importantes.

O jornal constitui-se como o orientador e organizador das ações, tal qual um fio de prumo para os pedreiros em uma construção. A intenção é que o jornal possa publicar os debates e as respectivas visões de cada grupo envolvido nele; as ações vitoriosas, as que não obtiveram sucesso -- e, portanto, não podem ser repetidas -- e, principalmente, as que sirvam de incentivo para outras lutas, em outras partes da nação que estejam em condições anteriores às divulgadas no periódico.

Entre os conteúdos desse jornal estariam:

- informações e trocas de experiências do estágio da luta entre as diferentes regiões;

- publicação de conteúdos que encorajassem o aperfeiçoamento do trabalho;

- publicação de denúncias políticas e econômicas (publicação da conjuntura) recolhidas por todo o país;

- dados para debates e leituras dos trabalhadores;

- informações que alimentassem intelectualmente os trabalhadores "de todas as profissões e de todos os graus de desenvolvimento".
Lenin (2010, p.253-254) alertava que esse processo de conscientização e organização do partido forneceria instrumentos para compreender melhor o momento histórico em que se encontravam as classes trabalhadora.

Outra consequência da organização de um jornal destinado à formação das classes trabalhadoras é que, desse trabalho de concepção, montagem e manutenção do jornal, se desenvolverá em uma flexibilidade (no partido ou na organização) que permita identificar os momentos em que o inimigo esteja com forças superiores e, assim, "evitar uma batalha em campo aberto". Da mesma forma, a organização teria condições de aproveitar os momentos em que esse inimigo estivesse enfraquecido e, tal qual uma guerrilha, atacá-lo no momento e local em que menos se espera. Lenin afirma que a criação de um jornal pode assegurar à organização a capacidade

[...] de, por um lado, evitar a batalha em campo aberto com um inimigo cujas forças são esmagadoramente superiores e concentradas num único ponto e, por outro, a capacidade de aproveitar a morosidade das movimentações do inimigo, como forma de atacar no momento e no local em que menos esperaria ser atacadado (ISKRA $\mathrm{n}^{\circ} .4$ in LENIN, 2010, p. 254).

Por isso, o jornal deveria circular com periodicidade, não só nos momentos em que, aparentemente, o conflito está nas ruas e há ações do "proletariado em armas", como também naqueles em que as classes trabalhadoras ainda não se encontram suficientemente conscientizadas como classe, ou, ainda, naqueles em que há derrotas (prisões e mortes) do movimento. 
Nos momentos em que o movimento está na defensiva, quando ocorrem muitas prisões ou assassinatos, o jornal faz-se muito necessário, pois, se não há um trabalho comum e regular, a onda de prisões e mortes pode continuar.

Ao contrário, se todas [as organizações] trabalhassem com objetivos comuns, mesmo se fossem muitas as prisões, bastariam algumas semanas de trabalho para restabelecer o contato dos novos círculos com o organismo central [...] e quando esse trabalho é comum, que se sente as consequências das prisões, é conhecido por todos, surgem e se estabelecem ligações com esse órgão central ainda muito mais rapidamente. (LENIN, 2010, p.256)

No caso do MST, após a fundação da União Democrática Ruralista (UDR), organização que representava os latifundiários, no meio da década de 1980, os conflitos acirraram-se no campo, pois a UDR financiava até milícias armadas. Depois, no final da década de 1990, além da campanha criminalizante por parte da indústria jornalística, o MST também sofreu massacres de seus integrantes, por meio de ações repressivas das polícias estaduais. Desses tristes momentos, o MST soube, tanto por meio de seu jornal como por suas místicas, manter ainda mais forte o espírito de luta dos seus militantes. As notícias sobre violência no campo ganharam uma coluna fixa, os militantes mortos tornaram-se personagens de referência e seus nomes batizam desde núcleos de trabalho até escolas nos assentamentos. Além disso, a data de um dos massacres sofridos pelo movimento, o massacre de Eldorado dos Carajás, em 17 de abril, foi transformada em dia internacional de luta.
Lenin (LENIN,2010, p. 257) encerra Que fazer? defendendo que a elaboração de um jornal não é trabalho de gabinete, ou seja, não é apenas uma revolução feita no papel, mas é condição para preparar e por em ação essa revolução na medida em que vai preparar os quadros envolvidos nela.

O interessante na história do Jornal Sem Terra é que, desde o primeiro número, ainda com o nome de Boletim da Campanha de Solidariedade aos Agricultores Sem Terra, é possível notar a orientação não de um partido no sentido clássico, mas de uma organização destinada a aglutinar as forças até então espontâneas dos agricultores sem terra.

\section{Jornal como instrumento para a organização do Movimento}

O primeiro veículo de comunicação do MST foi publicado na fase embrionária do movimento, resultado das lutas dos trabalhadores acampados na região de Ronda Alta, interior do Rio Grande do Sul. A fase embrionária do MST está inserida no contexto da reorganização dos movimentos da classe trabalhadora na fase final da ditadura militar brasileira. No campo, no caso específico do interior do Rio Grande do Sul, assim como no ABC Paulista, há um cenário de confluência entre agrupamentos de esquerda, sindicalistas e setores da Igreja Católica ligados à Teologia da Libertação. A modernização econômica, principalmente com a mecanização da produção agrícola, significou o desemprego para uma grande massa de trabalhadores rurais dependentes, 
à época, dos projetos de assentamento empreendidos pela ditadura militar. Esses projetos eram, na verdade, colonizações das regiões Centro-Oeste e Norte do Brasil.

Em Ronda Alta, Rio Grande do Sul, no segundo semestre de 1978, havia cerca de 350 famílias que não foram contempladas pelos processos de assentamento ocorridos de forma esporádica durante os anos de 1960 e 1970. Dessas famílias, cerca de 30 ocuparam a fazenda Sarandi, no município de mesmo nome, mas foram expulsas, porque a área era considerada reserva florestal, e retornaram aos acampamentos de origem.

De acordo com Morissawa (2001, p.124), foi a partir dessa fase que os trabalhadores sem terra começaram a discutir, realizar assembleias e analisar as saídas para os problemas que enfrentavam. Foi importante também a união desses trabalhadores com os militantes da Comissão Pastoral da Terra (CPT), grupo da Igreja Católica influenciado pela Teologia da Libertação. A CPT, e mais tarde o Camp (Centro de Assessoria Multiprofissional, entidade gaúcha formada por jovens militantes também ligados à Teologia da Libertação, além de estudantes e sindicalistas), juntamente com as paróquias das periferias das cidades e das comunidades rurais, passou a dar assistência aos trabalhadores rurais. Esses grupos de discussão e conscientização dos camponeses foram a semente do MST.

Morissawa (2001) descreve que, entre as decisões tomadas pelo grupo expulso da fazenda Sarandi, estavam a formação de comissões de base e de representantes e a criação de um abaixoassinado ao governador, reivindicando o assentamento no estado e informando que, se não fosse atendido, o grupo faria a ocupação de terras que haviam sido griladas, as glebas Macali e Brilhante. Como o governo não respondeu às reivindicações, as terras da Macali foram ocupadas, em setembro de 1979, por cerca de 110 famílias. Uma cruz fincada na terra era o símbolo da ocupação. Outras famílias remanescentes ocuparam a fazenda Annnoni, também em Sarandi.

Em dezembro de 1980, famílias que não foram assentadas nas lutas anteriores formaram um acampamento em um local chamado Encruzilhada Natalino, entroncamento das estradas que levam aos municípios de Sarandi, Ronda Alta e Passo Fundo. Outros trabalhadores rurais engrossavam a população do acampamento e, em sete meses, já havia cerca de 600 famílias, reunindo cerca de três mil pessoas.

Apesar de ficarem em barracos à beira da estrada, os acampados organizaramse em grupos, setores e comissões, e elegeram uma coordenação. É nesse processo que nasce o primeiro órgão de comunicação do movimento, o Boletim Informativo da Campanha de Solidariedade aos Agricultores Sem Terra, mais tarde chamado Boletim Sem Terra.

É sintomático o que seria o MST no futuro quando se considera que uma das primeiras ações da organização dos camponeses seja a criação de um veículo de comunicação direcionado tanto para os próprios acampados quanto para a sociedade civil, a qual o grupo pedia apoio. O primeiro jornal data de maio de 1981, com o nome de Boletim Informativo da Campanha de Solidariedade aos Agricultores Sem Terra. Eram 12 páginas datilografadas e distribuídas em cópias 
mimeografadas, cuja capa já trazia a expressão Sem Terra, que seria a marca de identidade do jornal até hoje.

Oboletim tinhafunção muito específica: informar sobre os acontecimentos no acampamento e organizar uma campanha de solidariedade, não só material, mas, principalmente, política. Parte pelo contexto político (uma organização ainda incipiente, em condições adversas, contra um adversário muito mais organizado) e parte pela influência das organizações de linha marxista, o resultado é que esses boletins, apesar de não terem nascido como instrumentos de um partido para organizar as massas, como apontava Lenin em Que Fazer?, continham seções que serviram como um "fio de prumo" para a organização do movimento naquela região.

A analogia que Lenin faz do jornal como um fio de prumo encaixa-se no período embrionário do movimento, em que as ações eram resultantes de conflitos contra um inimigo organizado e demandavam organização e, principalmente, apoio externo. $\mathrm{O}$ primeiro editorial mostra os planos do boletim:

O Boletim circulará periodicamente na intenção de manter 'aceso o fogo que clareia' as reivindicações dos trabalhadores rurais e também veicular todas as manifestações de apoio e solidariedade que tem recebido [...] "servirá, ainda, para que os agricultores renovem seu apelo à sustentação dessa luta e, ao mesmo tempo, manifestem o seu profundo e comovido agradecimento aos que nela, de uma forma ou de outra, já estão empenhados (BOLETIM SEM TERRA. No. 1, 1981)

Nas páginas 2 a 4, há o detalhamento da luta, sob o título História de um povo oprimido, desde as primeiras ocupações, e como os órgãos oficiais negligenciaram as reivindicações. No tópico $5^{\circ}$ do texto, pode-se perceber como o movimento passa a se organizar: uma comissão central formada por oito integrantes e subcomissões responsáveis pelos donativos recebidos, pelo saneamento (busca de fonte de água e tratamento do lixo) e outros pequenos grupos para discussão e reflexão.

O primeiro boletim segue relatando as diversas manifestações de solidariedade, não só de outros movimentos de agricultores, principalmente sindicatos de trabalhadores rurais de outros municípios e estados, como também de outros trabalhadores urbanos, o que seria também a marca do MST em toda sua história, a união dos trabalhadores da cidade e do campo.

$\mathrm{Na}$ página nove deste boletim, ainda dessa questão da análise das situações regionais, é publicada uma pequena nota sob o título Um alerta dos trabalhadores rurais da Bahia. Ao manifestar solidariedade aos acampados do sul, o Sindicato dos Trabalhadores Rurais da Bahia alertou que os agricultores expulsos quando da construção da barragem de Sobradinho foram colocados na Serra do Ramalho, região que não apresentava condições para agricultura. O boletim usa esse exemplo para que os agricultores do Sul não aceitassem essa proposta do INCRA.

Nessa fase, o boletim servia tanto de subsídio para os agricultores acampados, para que não aceitassem a proposta do Governo, como para informar aos demais setores da sociedade os motivos que levavam os trabalhadores rurais a continuar protestando. Ao longo da história, essa publicação impressa 
continua com essa dupla função (falar para a base e para a sociedade de apoio) até metade da década de 90, quando a exposição nacional do MST por meio da indústria jornalística cresce de tal maneira que força o movimento a pensar em outras formas de comunicação, tanto para combater a criminalização empreendida pela indústria jornalística como para fazer seus valores chegarem a um público que ainda não o apoiava.

$O$ boletim continua sendo publicado quinzenalmente e a evolução do seu conteúdo passa pelo desenvolvimento tecnológico e, principalmente, pelo contexto político da organização dos camponeses. É importante destacar que, mesmo sendo uma publicação orientada pelas organizações que prestavam "assessoria" aos camponeses, a cultura popular, principalmente a religiosidade e a ligação com a terra, foi incorporada à redação e ao "planejamento gráfico", o que contribuiu para o fortalecimento da publicação.

O número 3 do Boletim Sem Terra, de junho de 1981, traz, pela primeira vez, a explicação sobre a simbologia adotada pelo movimento. Nos primeiros acampamentos, uma cruz era fincada na terra, representando o "sofrimento, as glórias e a esperança" (consequência da influência da Teologia da Libertação) e, assim, foi feito na Encruzilhada Natalino.

Em maio de 1981, ocorreu a primeira morte de uma criança, Loivaci Pinheiro, de quatro meses, vítima de pneumonia, subnutrição e falta de cuidados médicos. Para marcar esse episódio, é acrescentado à cruz um lençol branco. Depois, a cada criança que morria no acampamento, um novo lençol branco era amarrado à cruz, que, em vez de ser cravada na terra, passou a ser amparada por escoras que simbolizavam os apoios recebidos.

A cruz escorada e com os panos brancos amarrados foi o primeiro dos diversos símbolos da luta dos trabalhadores rurais, como a bandeira, o hino e as canções que constituem a mística do movimento

[A mística] No contexto dos sem terra, é um ato cultural em que suas lutas e esperanças são representadas. As palavras de um integrante do Movimento resumem bem a ideia da mística: 'nas lutas sociais existem momentos de repressão que parecem ser o fim de tudo. Mas, aos poucos, como se uma energia misteriosa tomasse cada um, lentamente as coisas vão se colocando novamente e a luta recomeça com maior força. Essa energia que nos anima a seguir em frente é que chamamos de mistério ou mística. Sem que algo se move em direção a um ser humano para torna-lo mais humano aí está se manifestando a mística. (MORISSAWA, 2001, p. 209)

No boletim número 3, pela primeira vez, é publicada uma foto. O tema é o enterro da menina Loivaci. Apesar das páginas internas ainda serem datilografadas na forma de um texto corrido, a capa apresenta características de um jornal.

A adoção da cruz com os panos brancos amarrados e as escoras não só identifica o acampamento como "comunica" a toda sociedade que ali há sofrimento (caracterizado pela própria cruz), há desejo de paz (pelo uso do branco) e há, principalmente, apoios, pois as organizações que manifestam solidariedade têm os nomes gravados nas escoras.

No boletim número 22 , de maio de 1982, pela primeira vez, ao lado do cabeçalho, aparece a cruz com os panos amarrados, que simboliza a luta nos 
acampamentos.

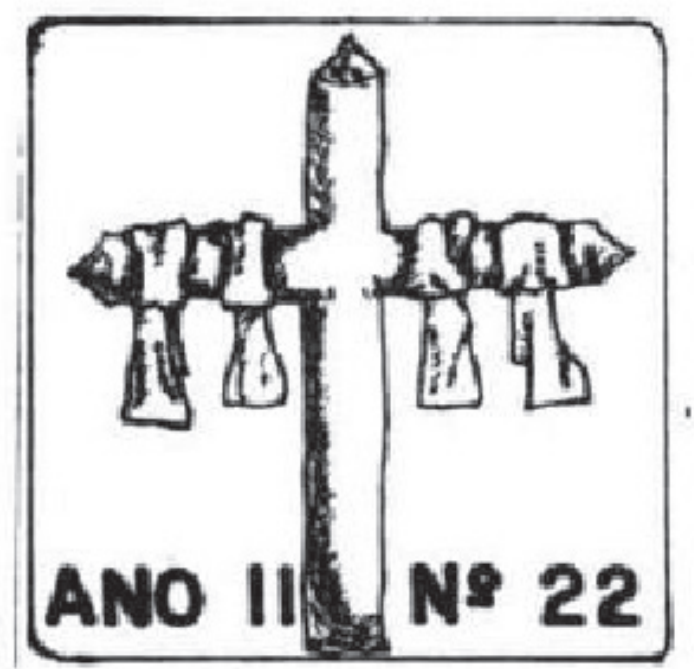

Fig. 1- Símbolo da luta que caracteriza o movimento ao lado do cabeçalho

A religiosidade está muito presente nesses boletins. Não só pela presença da cruz e pela matéria sobre a campanha de arrecadação de fundos nas paróquias do Estado, mas também pela referência à luta no novo acampamento como luta pela terra prometida.

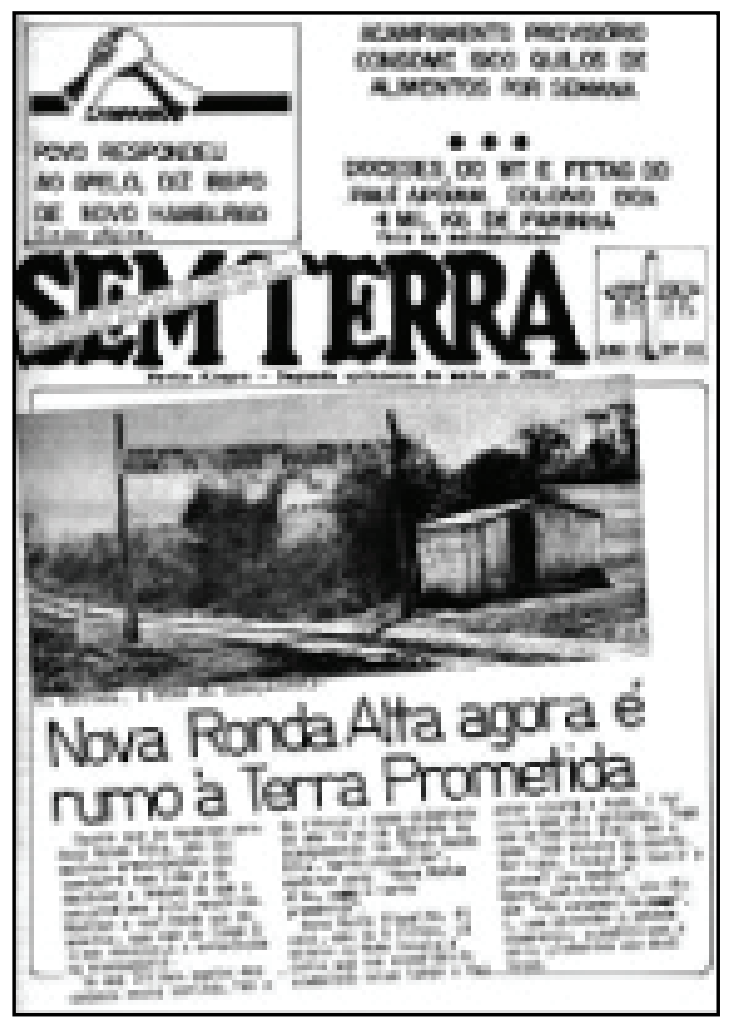

Fig. 2 Referências religiosas no boletim 22. Influência da Teologia da Libertação
No decorrer de sua evolução, a política de comunicação não deixa de incorporar essa cultura popular do camponês. Com o distanciamento do movimento da Igreja e com o enfraquecimento da Teologia da Libertação, a prática de celebrações transforma-se em momentos de reflexão que são chamados de mística. (MENEZES NETO, 2012). É interessante notar que a mística não acontece apenas em "encenações teatrais" nas reuniões, encontros, congressos e capacitações. Assim como nesses primeiros boletins, foi incorporada à criação de simbologias e permanece no processo editorial, quando, por exemplo, se pensa no rol de músicas que serão executadas na rádio comunitária ou quando um texto é escrito.

A luta dos trabalhadores rurais no Sul do país seguiu por três anos, até 1984. De maio de 1981 a julho de 1982, o boletim foi publicado quinzenalmente. A partir do número 25, de julho de 1982, o boletim passa a ser publicado mensalmente e, com raras exceções, manteve essa periodicidade por 30 anos.

No boletim número 20, há um infográfico com o organograma da organização. Não há nomes, mas mostra como estão os setores, todos abaixo da Assembleia do Povo, a instância maior, convocada pelo menos uma vez por mês para votação dos assuntos principais, leitura de comunicados e que se reúne na "choupana da democracia", uma palhoça no centro do acampamento, feita com varas de bambu e coberta de palha, semelhante a uma construção indígena.

Essa foi a primeira instalação do novo acampamento. Abaixo da assembleia, estão os líderes do grupo de famílias e a comissão central, responsável pela execução das decisões. Entre as equipes 
de trabalho - lavoura, rancho, água, animais -, é significativo que conste, ao lado da segurança, a de imprensa. O que mostra a preocupação do movimento com a comunicação. Pode ser considerado relevante que, rurais dos estados do Sul, o que resultaria experiências" para os demais movimentos de trabalhadores rurais que existiam no Brasil.

Os boletins contribuíram para unificar a luta, pelo menos dos trabalhadores

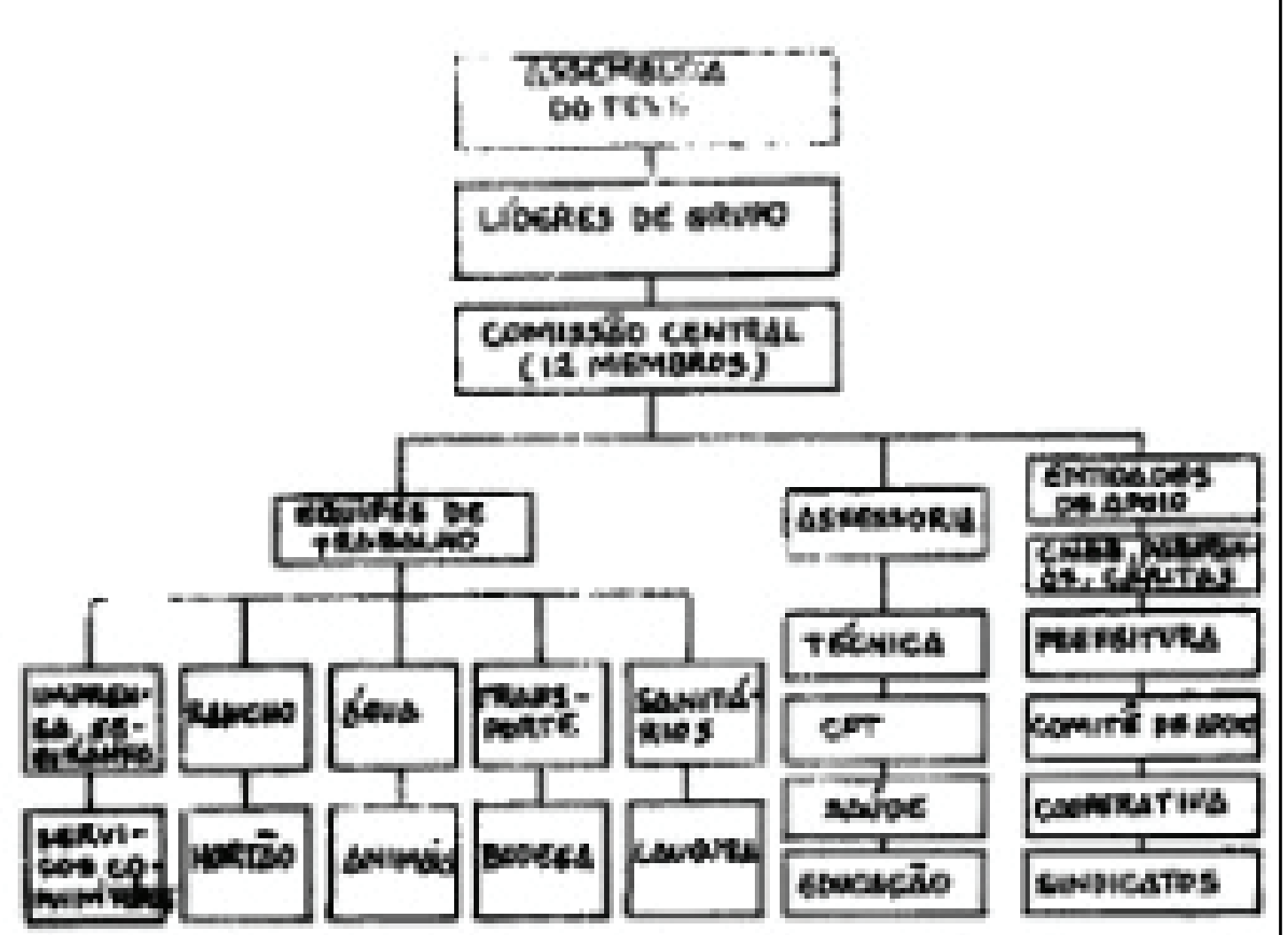

Fig. 3. Organograma publicado na edição 20, destaque para a equipe de imprensa, ao lado de outras equipes de trabalho como rancho, lavoura e animais

em um momento de intensa repressão e ainda sob a ditadura militar, o boletim traga, mesmo sem nomes, a estrutura e organização do movimento. Mesmo que isso significasse atrair a atenção das forças de repressão, os textos do boletim cumpriam duas tarefas: a primeira, mostrar para a sociedade como o movimento trazia uma mensagem de democracia e de paz, ao contrário da forma como o Estado agia contra ele e contra outros setores; a segunda, e a mais importante do ponto de vista ideológico, mostrar, aos demais movimentos de trabalhadores rurais, uma forma de agir. O jornal, nessa fase, ainda funcionava como uma "troca de na formação de uma organização que englobava os lavradores do Rio Grande do Sul, Santa Catarina, Paraná, São Paulo e Mato Grosso do Sul, que daria origem, em 1984, ao MST.

O suplemento especial do Boletim dos Sem Terra, de novembro de 1982, além de trazer um encarte com explicações sobre a Lei de Segurança Nacional, cuja revogação era uma das bandeiras dos movimentos sociais da época, é dedicado ao primeiro encontro nacional e traz, na última página, a Carta de Goiânia, documento final do seminário realizado no centro de formação da Diocese de Goiânia, que expressa os objetivos do que seria, dois 
anos após, o MST.

A partir desse suplemento, ainda sob o nome de Boletim Sem Terra, e depois, a partir do número 36 , já com o nome de Jornal Sem Terra, o veículo passa a ter, como colunas fixas, as notícias do movimento nos diversos estados em que está organizado, promove intercâmbio de experiências de luta não só pelo Brasil, mas também pela América Latina, além de trazer análises das conjunturas regionais e nacionais.

Dessa forma, pode-se dizer que a publicação torna-se um organizador político, não necessariamente como Lenin descrevia, já que não havia a condução por um "partido", mas a publicação foi de grande importância no intercâmbio de informações, na troca de experiências, na publicação de debates internos e de documentos que serviam de fio condutor para as ações nos estados.

No número 33, de novembro de 1983, o editorial soa como marco do último informativo, assinado como Regional Sul, antes da formação do Movimento dos Trabalhadores Sem Terra. Faz um balanço do que foi a conquista em Ronda Alta, explicitando os setores que dão base ao movimento em oposição aos que são considerados inimigos.

Ficará escrito na História o enfrentamento do direito ao trabalho, à justiça contra a exploração e opressão. [...] De um lado a solidariedade de milhões de trabalhadores, de outro o oportunismo e acusações das autoridades e políticos do Governo. Registrará que foi a luta pela terra para trabalhar contra o êxodo rural e a colonização desumana e cruel. Dirá que de um lado estava a igreja da libertação, dos oprimidos, de Medellin e Puebla; do outro a Igreja dos poderosos, dos opressores, de
Trento. De um lado os sindicatos autênticos e solidários, do outro os pelegos e traidores. Ficará marcado como a luta da união e da organização contra a repressão e a violência (BOLETIM SEM TERRA, número 33, p.1).

E faz uma chamada para novos movimentos: "Resta a esperança de milhões que a História continue registrando a profecia de Ronda Alta: 'se continuarem unidos e organizados, eu, em nome de Deus, lhes prometo a terra"'. (idem)

A numeração foi mantida no Jornal Sem Terra nos anos seguintes, caracterizando a continuidade do órgão criado durante o acampamento na Encruzilhada Natalino. Entre outros significados, esse respeito ao Boletim Informativo da Campanha de Solidariedade aos Agricultores Sem Terra mostra que o MST é um movimento com forte presença da base, que valoriza as origens, a história do povo e das lutas. A partir desta edição, o jornal, aos poucos, mescla conteúdos informativos pontuais com textos de reflexão, mais indicados para um processo de formação das bases até se tornar hoje mais um instrumento de formação da base do que um órgão informativo (BARBOSA, 2013).

\section{Considerações finais}

A história da imprensa operária oferece vários exemplos da falta de continuidade dos seus órgãos de comunicação. Por exemplo, em Que Fazer? (2010), Lenin relata as cisões e diferenças entre os jornais das diferentes tendências e suas mudanças ao longo do tempo, como o Iskra (A Centelha) e o Rabotcheie Dielo (A Causa Operária). No livro Jornalistas 
e Revolucionários, Bernardo Kucinski (2003) descreve as diversas cisões que ocorreram entre os jornais da imprensa alternativa por razões ideológicas ou econômicas.

No caso do MST, ao se iniciar o Jornal Sem Terra, um pensamento simplista poderia considerar que a conquista do assentamento em Ronda Alta significaria o fim daquele periódico e o começo de outro, mas, como o movimento entende que a luta não se restringe à conquista da terra, e sim passa por mudanças na sociedade e na política econômica, a luta não acabava com o assentamento, pelo contrário, começava uma nova etapa, que se encaixava na proposta do novo jornal. Graças à assessoria da Comissão Pastoral da Terra (CPT), os trabalhadores rurais foram além do antagonismo em relação ao latifundiário, da reivindicação imediata e, aos poucos, foram se aproximando do nível político ao inserir a luta pela terra em um contexto maior, no do conflito entre capital e trabalho.

Aos poucos, a partir da segunda metade da década de 1990, a política de comunicação do MST vai se transformando e o Jornal Sem Terra torna-se um veículo voltado para a base e, paulatinamente, vai incluindo conteúdos mais voltados para a formação. Além do fato de o Movimento ter de dar conta dos novos atores que se incorporavam aos seus quadros, $\mathrm{o}$ contexto político, com a hegemonia do modo de produção capitalista na América Latina, não era favorável aos demais movimentos sociais. Com as crises dos demais movimentos populares, e, mais tarde, com o duro embate ideológico contra o agronegócio, o MST sentiu a necessidade de preocupar-se, cada vez mais, com a formação dos seus quadros, não só no ensino básico, mas também no ensino técnico e superior. 


\section{Referências bibliográficas}

BARBOSA, Alexandre. A comunicação do MST: uma ação política contrahegemônica. 2013. Tese (Doutorado em Interfaces Sociais da Comunicação) - Escola de Comunicações e Artes, Universidade de São Paulo, São Paulo, 2013. Disponível em: <http://www.teses.usp.br/teses/disponiveis/27/27154/tde-26022014-120204/>. Acesso em: 2014-03-18.

GRUPPI, Luciano. O conceito de hegemonia em Gramsci. Trad. Carlos Nelson Coutinho. Rio de Janeiro: Edições Graal, 1978.

KUCINSKI, Bernardo. Jornalistas e revolucionários: nos tempos da imprensa alternativa. São Paulo: Edusp, 2003.

LENIN, V.I. Que fazer? Problemas candentes do nosso movimento. Trad. Marcelo Braz. 1ed. São Paulo: Expressão Popular, 2010.

MORISSAWA, Mitsue. A história da luta pela terra e o MST. São Paulo: Expressão Popular, 2001.

MENEZES NETO, Antonio Julio de. A ética da Teologia da Libertação e o espírito do socialismo no MST. Belo Horizonte: Editora UFMG, 2012.

MOVIMENTO DOS TRABALHADORES RURAIS SEM TERRA. BOLETIM SEM TERRA. Porto Alegre. Números 01-35, maio/1981-abril/1984.

. Carta do $5^{\circ}$ Congresso Nacional do MST. Disponível em <www. mst.org.br>. Acesso em 06 jan. 2012.

JORNAL SEM TERRA. Porto Alegre /São Paulo. Números 36316, julho/1984-dezembro/2011.

. JORNAL DAS CRIANÇAS SEM TERRINHA. São Paulo. Números

01-24, outubro/2007-fevereiro/2011.

.MST: Lutas e Conquistas. São Paulo: Secretaria Nacional do MST,

2010.

Este artigo e todo o conteúdo da Estudos em Jornalismo e Mídia estão

disponíveis em https://periodicos.ufsc.br/index.php/jornalismo

Estudos em Jornalismo e Mídia está sob a Licença Creative Commons 2.5 